\title{
Dentin hassasiyeti ve tedavi yöntemleri
}

\section{Dentin hypersensitivity and treatment methods}

\author{
Hasan Guney Yilmaz, DDS, PhD, ${ }^{a}$ Hakan Bayindir, DDS, ${ }^{a}$ Esra Cengiz, DDS, ${ }^{b}$ Atilla Berberoğlu, \\ DDS, $\mathrm{PhD}^{\mathrm{a}}$ \\ ${ }^{a}$ Yakın Doğu Üniversitesi, Dişhekimliği Fakültesi, Periodontoloji Anabilim Dalı, Lefkoşa, KKTC. \\ ${ }^{\text {b} Y a k ı n ~ D o g ̆ u ~ U ̈ n i v e r s i t e s i, ~ D i s ̧ h e k i m l i g ̆ i ~ F a k u ̈ l t e s i, ~ D i s ̧ ~ H a s t a l ı k l a r ı ~ v e ~ T e d a v i s i ~ A n a b i l i m ~ D a l ı, ~ L e f k o s ̧ a, ~ K K T C . ~}$
}

Received: 28 January 2011 Accepted: 14 May 2011

\begin{abstract}
ÖZET
Günümüzde giderek artan bir sorun olarak karşımıza çıkan dentin hassasiyeti (DH) herhangi bir dental defekt veya patoloji ile açıklanamayan, kimyasal, termal, temas, ozmotik veya buharlaştırıcı uyarana karşı ortama açılmış dentin yüzeylerinden yayılan, kısa süreli keskin bir ağrı olarak tanımlanmaktadır. Sert doku kaybı veya dişeti çekilmesiyle dentin yüzeyinin açı̆̆a ve dentin kanallarının oral kaviteye doğru açılmasıyla DH oluşabilir. Evde veya klinikte uygulanacak tedavinin belirlenmesinden önce tedavi planı etiyolojik faktörler ve hastanın oral hijyen alışkanlıkları da dikkate alınmalıdır. Tedavi ekspoze dentin kanallarını kapatarak tübüllerdeki sıvı akışını azaltmaya ve pulpadaki sinir iletimini bloke eden desensitivite edici birçok kimyasal ya da lazerlerin de dahil olduğu fiziksel ajanların kullanımına dayalıdır. $\mathrm{Bu}$ derleme dentin hassasiyetinin tanımı, epidemiyolojisi, mekanizması, etyolojisi, teşhis ve tedavi protokolleri tanımlamaktadır.

Anahtar Kelimeler: Dentin hassasiyeti, etiyoloji, teşhis, lazer, desensitivite edici ajan.
\end{abstract}

\begin{abstract}
Dentin hypersensitivity (DH) is a relatively common problem experienced in clinical dental practice. This condition has been defined as a short, sharp pain arising from exposed dentin in response to stimuli typically thermal, evaporative, tactile, osmotic or chemical and which cannot be described to any other form of dental defect or pathology. DH may ocur as a result of exposed dentinal tubules through either loss of enamel or gingival recession. Management strategies, which take into account aetiological factors and patient's oral hygeine behaviour, should be considered before the home or in office treatment protocols. Treatment plan should include reduce fluid flow in the tubules by means of occlude exposed tubules and block the nerve response in the pulp with many desensitizing chemical agents or phyisical agents which also include lasers. The purpose of this review is to summarize the definition, epidemiology, mechanism, aetiology, diagnosis and treatment protocols of dentin hypersensitivity.
\end{abstract}

Key words: Dentine hypersensitivity, aetiology, diagnosis, laser, desensitizing agents.

\section{Prevelans ve Etiyoloji}

Günümüzde giderek artan bir sorun olarak karşımıza çıkan dentin hassasiyeti herhangi bir dental defekt veya patoloji ile açıklanamayan, kimyasal, termal, temas, ozmotik veya buharlaştırıcı uyarana karşı

Hasan Güney YILMAZ,

Yakın Doğu Üniversitesi, Dişhekimliği Fakültesi, Periodontoloji AD,

Lefkoşa, KKTC

Tel: 03926802030/2654 Faks: 03926802025

e-posta: guneyyilmaz@hotmail.com ortama açılmış dentin yüzeylerinden yayılan, kısa süreli keskin bir ağrı olarak tanımlanmaktadır. ${ }^{1}$ Dikkatli bir muayene ile elde edilen dentin hassasiyeti oranı yaklaşık \%15 olarak bildirilmiştir Periodontal hastalığ 1 olan bireylerde bu oran \%70-98 arasında değişmektedir., ${ }^{2,3}$ Genelde 20-40 yaşlarında görülse de 70' li yaşlara kadar dağılım gösterebilir. Dentin hassasiyeti genç yetişkinlerde en yüksek oranda prevalansa sahip iken artan yaşla birlikte bu prevalans düşmektedir. Dentin ve pulpada yaşa bağlı olarak gelişen 
sklerotik ve sekonder dentin yapımı gibi değişiklikler, hassasiyet seviyesinde görülen bu farklılıkları açıklamaktadır. Kötü oral hijyene sahip popülâsyona göre iyi oral hijyene sahip popülâsyonlarda prevalans daha yüksektir. ${ }^{4,5}$ Genellikle dentin hassasiyeti kadınlarda erkeklere göre daha yüksek oranda görülmektedir. $\mathrm{Bu}$ durum kadınların erkeklere göre daha iyi ağız ve diş bakımı sağlamaları ve diş firçalama alışkanlıklarına daha bağlı olmalarıyla açıklanabilir. ${ }^{6,7,8}$ Kanin dişler, I. premolarlar, anterior dişler, II. premolarlar sirasıyla en çok etkilenen dişlerdir. En az etkilenen dişler molarlardır. Dişlerin daha çok bukkal servikal bölgeleri etkilenir. Ancak dentin aşırı hassasiyeti herhangi bir dişte herhangi bir yüzeyde de görülebilir. En s1k lokalizasyonu vestibüle yakın servikal marjindir, bununla birlikte hassasiyetin lingual, palatinal bölgelerde ve tüberkül yüzeylerinde de görüldüğü bildirilmiştir., $3,6,7,9$

Dentin hassasiyetini açıklama birçok teori ileri sürülmüştür. Bunlar: dentin reseptör mekanizması, odontoblastik transdüksiyon teorisi ve dentin tübüleri içerisindeki sıvının hareketiyle oluşan ağnı geniş olarak kabul gören Brännström ve Aström tarafinda ortaya konan hidrodinamik teoridir. Hidrodinamik teoriye göre her türlü uyarı dentin tübülleri içerisindeki dentin sıvısının hidrodinamik hareketi ile pulpaya iletilmektedir. Isısal, fiziksel veya ozmotik değişimler dentin sıvısı hacminin değişimine veya hareketine neden olarak bir basınç reseptörünü uyarır ve bu da sinirler üzerinde impuls oluşturur. Uyaranın cinsine göre (termal, ozmotik, elektriksel, kimyasal) dentin tübülleri içerisindeki sıvı ya pulpa yönünde ya da dışarı doğru hareke etmekte ve pulpaya iletilmektedir. ${ }^{1,3,4,7,10}$ Elektron mikroskobu incelemelerinde hassas olan bölgelerdeki dentinin, hassasiyet belirtisi olmayan bölgelerdeki dentine göre daha geniş çaplı ve ortamla bağlantısı olan dentin tübülleri içerdiği gösterilmiştir. $\mathrm{Bu}$ da stimülüs iletimini hidrodinamik teoriyle açıklayan hipotezi desteklemektedir. ${ }^{1,8,11} \mathrm{Bu}$ sonuçlardan da anlaşılacağı üzere, dentin hassasiyetinin oluşması için mine veya sementin kaybıyla, dişeti çekilmesiyle veya her ikisinin kombinasyonuyla dentin tübüllerinin ağız ortamına açılmış olması gerekir. Bununla birlikte ortama açılmış her dentin yüzeyinde hassasiyet olması gerekmez, hastanın yaşı, fizyolojik ve psikolojik durumu, ağrı eşiği, tükrük içerisindeki proteinlerin, dentin tübüllerindeki kalsiyum fosfatın çökelmesi ve pulpaya yakın bölgede tamir dentini oluşması gibi faktörler dentin hassasiyeti oluşumunu etkileyebilir. ${ }^{12,13}$

Erozyon, abrazyon, atrizyon ve abfraksiyon lezyonları dentin tübüllerinin açığa çıkmasına neden olan sert doku kayıplarıdır. Atrizyon yaşa bağlı olarak insizal, oklüzal ve bazen proksimal yüzeylerde de görülen, bruksizm gibi parafonksiyonel aktiviteler ile şiddeti artan fizyolojik aşınmalardır., ${ }^{6,10,14}$ Abrazyon, yabancı bir cisim ile diş yüzeyinin aşınmasıdır. Yoğun kuvvet uygulanarak yapılan özellikle eroziv asit atağı sonras1 firçalama abrazyona sebep olabilir., ${ }^{4,6,14}$ Diş aşınmasının en büyük etkeni olarak sayılan erozyon ise bakteriyel orijinli olmayan asitlerle diş yüzeyinin aşınmasıdır. İnorganik matris gastrit reflü hastalarında içsel (hidroklorik asit), yiyecek ve içeceklerden kaynaklanan dişsal asitler (sitrik asit, malik asit, fosforik asit) vasitasıyla demineralize olur. Böylece minenin çözünürlüğü artar, yapısından demineralizasyonla kalsiyum kaybı başlar, abrazyonlara direnç azalır., ${ }^{6,13}$ Son olarak abfraksiyondan söz edilebilir. Oklüzal parafonksiyonel kuvvetlerin bask1 ve gerilim stresleri sonucu servikal bölge zayıflar ve buna bağlı çatlak ve kırıklar oluşarak abrazyon ve erozyonun oluşmasında predispozan faktör olarak rol alır. ${ }^{10,14,15}$ Dentin hipersensitivitesinin bir diğer sebebi de dişeti çekilmesiyle kökün açığa çıkması, sementin kolayca aşınarak dentin kanallarının ağız ortamına açılması gösterilebilir. Travmatik firçalama, periodontal hastalıklar sonucu periodontal 
dokulardaki yıkım, restorasyonların marjinal uyumunun bozulması, diş malpozisyonları, scaling ve kök düzlemesi, cep eliminasyonunu, kron boyu uzatma işlemlerinin içeren cerrahi ve cerrahi olmayan periodontal tedaviler dişeti çekilmesiyle sonuçlanabilir. ${ }^{3,6,16}$

Dentin hassasiyetinde termal uyaranlar, osmatik uyaranlar ve fiziksel uyaranlar sonucu k1sa süreli, keskin ve rahatsız edici ağrı şikâyeti oluşturmaktadır. ${ }^{1,12,15}$ Dikkatli klinik ve radyografik muayene dentin hassasiyetini dişleri etkileyen diğer patolojilerden ayrılmasını sağlar. $\mathrm{Bu}$ patolojiler; genellikle posterior dişlerde görülen çiğneme esasında da kısa ve ağrılı cevap veren çatlak diş sendromu, çatlak restorasyonlar, çürükler, post-operatif hassasiyet, akut hiperfonksiyonlu diş, palato-gingival oluk, konjenital olarak açık mine sement birleşimi, pulpanın reversibl veya irreversibl enflamasyonları, vital ağartma sonrası oluşan hassasiyettir. ${ }^{4}$ Teşhiste hava spreyi, soğuk su gibi is1 testleri, sond ile muayene, radyografi, perküsyon testi, 1sırma stres testi, oklüzyon değerlendirilmesi, ayırıcı anestezi testi, transillüminasyon gibi yöntemler kullanılabilir. $^{10,12,17}$ Genel olarak hassas bölgelerde mekanik veya termal stimulusların sond ve hava-su spreyiyle uygulanması ardından hastaların verdiği cevapların değerlendirilmesinde görsel karşılaştırma skalası (VAS) ya da şiddetli, orta, hafif gibi kelimelerle ağrının tanımlandığı sözel tanımlama skalası kullanılır (VRS). VAS hastalara doğru anlatıldığında hipersensitive değerlendirilmesinde anlaşılır, ağrı yoğunluğunun ölçülmesinde ve tedavilerin etkinliğinin değerlendirilmesinde hassas ve kullanımının kolay olduğu yapılan çalışmalarda belirtilmiştir. ${ }^{3,4,7,18}$

\section{Tedavi Yöntemleri}

Dentin hassasiyeti tedavisinde çok sayıda tedavi seçeneği ve desensitivite edici ajan bulunmaktadır. Bu materyaller ve tedavi yöntemleri kullanılırken, Grossman` 1n, ideal desensitize edici ajanda aranılan; pulpaya irritan olmamalı uygulama sırasında ağrı yaratmamalı, kolaylıkla uygulanabilmeli, etkinlik süresi uzun olmalı, hızlı etki etmeli, dişlerde renklenme yapmamalı etkinliği kalıcı olmalı önermeleri göz önünde bulundurulmalıdır. ${ }^{3}$ Tedavi genel olarak dentin tübüllerindeki sıvı akışını azaltmak ve sinir iletimini bloke eden ajanların kullanımına dayalıdır. Dentin hassasiyetinin tedavisi problemin derecesine göre hekimler tarafindan ya da evde hasta tarafindan uygulanabilir. Bunlardan evde bireyin kendi uyguladığ 1 tedaviler hassasiyet giderici diş macunları ile yumuşak kıllı diş fırçaları ve ağız gargaralardır. $\mathrm{Bu}$ amaçla ilk kullanılan diş macunları içine eklenen sodyum monoflorofosfat, sodyum florür ve kalay florür gibi florür bileşikleri reminelarizasyonu arttırır ve açık dentin yüzeyinde çökelerek dentin tübüllerini tıkarlar. ${ }^{4,19,20}$ Son zamanlarda ise çoğu hassasiyet giderici diş macunlarının, potasyum nitrat, potasyum klorür, potasyum sitrat ve potasyum oksalat gibi potasyum tuzları içerdiği bilinmektedir. Potasyum iyonlarının dentin tübülleri boyunca yayıldığını ve A sinir liflerinin membran potansiyelini değiștirerek sinir iletimini azalttığı düşünülmektedir. ${ }^{10,19,20}$ Diş macunlarındaki abrazivler (kalsiyum karbonat, aluminyum, kalsiyum fosfat, silikat) direkt olarak tübül obliterasyonuna sebep olurlar ya da firçalama sırasında oluşan smear tabakası oluşumuyla indirekt olarak obliterasyona yardımcı olurlar. 3,10 Son olarak birkaç yeni kimyasal formül dentin hassasiyetini azaltmak amaciyla üretilmiştir. Bunlar açık dentin kanallarını kapatarak dentin hassasiyetiyle ilişkili dış stimulusları bloke eden arginine-kalsiyum karbonat, ${ }^{21}$ kalsiyum-sodyum fosfosilikat biyoaktif cam, ${ }^{22}$ karbonize hidroksiapatit nanokristallerdir. ${ }^{23,24}$ Ayad ve ark., ${ }^{21}$ tarafından yapılan klinik çalışmada $\% 8$ arginine, kalsiyum karbonat ve 1450 ppm florid olarak sodyum monoflorofosfat içeren diş macunuyla günde iki kere firçalamanın üç gün içerisinde hassasiyette 
anlamlı bir azalmaya sebep olduğu gösterilmiştir. Yeni kimyasal bileşimlerden bir tanesi olan kalsiyum-sodyum fosfosilikat, biyoaktif camdır ve ağız ortamıyla etkileştiğinde mine ve sementteki yapıya kimyasal olarak benzeyen hidroksi-karbonat-apatit oluşturan kalsiyum ve fosfat iyonları açığa çıkararak demineralizasyonu azaltır. ${ }^{22}$ Pradeep ve ark. \%5 potasyum nitrat içeren diş macunu ve \%5 kalsiyum-sodyum fosfosilikat içeren diș macunlarını kilinik etkinliğini 110 hasta üzerinde altı hafta boyunca değerlendirmiş ve kalsiyumsodyum fosfosilikat içeren diş macunu kullanımının, potasyum nitrat içeren diş macununa göre daha üstün oranda hassasiyette azalma gösterdiğini bildirmişlerdir. $^{22}$ Son olarak karbonize hidroksiapatit nanokristalleri, hassasiyet tedavisinde diş macunlarıda kullanılmaya başlanmıştır. Sentetik karbonize HA nanokristallerinin mine yüzeyinde in vitro remineralizasyonları ve dentin kanallarını kapatmada etkili oldukları gösterilmiştir. ${ }^{23,24}$ Hassasiyet giderici diş macunlarıyla diş firçalama sonrası su ile ağzın çalkalanmasının aktif ajanın seyreltilip ağıdan uzaklaşmasına neden olduğu ve böylece beklenen etkiyi azaltacağı hastaya anlatılmalıdır. ${ }^{3,7}$ Hassasiyet tedavisinde hastanın evde uygulayabileceği diğer preparatlar arasında potasyum klorit içeren sakızlar ve potasyum sitrat, potasyum nitrat ve sodyum florür içeren gargaralar say1labilir. ${ }^{4,26}$ Pereira ve ark. 50 hasta üzerinde yaptıkları klinik kontrollü bir çalışmada $\% 3$ potasyum nitrat ve $\% 0,2$ sodyum florür içeren gargaranın altı hafta boyunca günde iki defa kullanımı sonucunda dentin hassasiyetinden doğan rahatsızlığın azaltılmasında etkili olduğu gösterilmiştir. $^{26}$

Evde, 2-4 hafta süre ile devam edilen DH tedavisine rağmen, ağrı şiddetinde bir değişme meydana gelmemiş ise tedaviye klinik ortamda devam edilmesinin etkili ve başarılı olduğu bildirilmiştir. ${ }^{7}$ Klinik olarak DH nin tedavisinde; sinirin duyarsızlaștırılması, anti-inflamatuar ajanlar ve dentin tübüllerinin kaplanması veya tıkanmasını sağlayacak çeşitli kimyasal ve fiziksel ajanlar kullanılmaktadır. ${ }^{8} \mathrm{Bu}$ ajanlardan sinirin duyarsızlaştırılması için kullanılanı potasyum nitratın etki mekanizmasının oksidasyon ya da tübülleri kristalleştirerek sinir iletimini bloke etmek şeklinde olduğu düşünülmüş ancak kanıtlanmamıştır. Bir diğer olası mekanizma ise, yüksek miktarlarda uygulanan potasyum iyonlarının ekstraselüler potasyum konsantrasyonunu artırdığ membranların depolarize ederek sinirlerin uyarılmas1 ve bunu ileride aksiyon potansiyeli yayılımında bir blokaj oluşturduğu belirtilmiştir. ${ }^{4,10,25,26} \mathrm{Bu}$ bulguların tersine Orchardson ve Gillam bu önerinin sağlam insan dişlerinde henüz doğrulanamadığını bildirmişlerdir. ${ }^{27}$

Antiinflamatuar ajanlardan biri olan kortikosteroidlerin dentin hassasiyeti tedavisinde kullanılması önerilmiş, yapılan çalışmalarda tam olarak etkililiği kanitlanmasa da dentin tübüllerinin tıkanmasında mineralizasyonu arttırarak hassasiyeti azaltacakları düşünülmüştür. Günümüzde bu ajanların kullanımı hala sorgulanmaktadır. ${ }^{2,8}$

Dentin tübüllerini kapatan ve tıkayan ajanlara sırasıyla bakılacak olursa ilk olarak kalsiyum bileşiklerinden söz edilebilir. Etki mekanizmasının, kalsiyum iyonlarıyla protein yapıyı çözmek ve mineralizasyonu arttırarak dentin tübüllerini tıkamak şeklinde olduğu gösterilmiştir. Kalsiyum hidroksit çabuk etki göstermekle birlikte uygulamanın tekrarlanması gerekliliği ve gingival dokular üzerine irritasyonu olumsuz özellikleri olarak söylenebilir., ${ }^{2,8}$ Bir diğer desensitivite edici ajan kalsiyum -fosfat iyonları ağız ortamında bulundukları zaman minede remineralizasyon sağlarlar. ${ }^{7}$ Yapılan çalışmalarda kalsiyum fosfat bileşiğinin dentin tübülleri ağzını kapattığ ve geçirgenliği azaltarak hassasiyeti önlemede etkili olduğunu bildirilmiştir. ${ }^{28,29}$ Kazein fosfopeptid ve amorf kalsiyum 
fosfat bileşimi de dentin hassasiyeti tedavisinde kullanılmıştır. Amorf kalsiyum fosfat suda çözünerek kalsiyum fosfat iyonlarına ayrışarak etki ettiği öne sürülmüştür; ancak Yates ve ark. plasebo kontorllü split- mouth bir çalışmada amorf kalsiyum fosfatın etkinliğinin 84. gün kontrolde plaseboya göre anlamlı bir fark oluşturmadığını belirtilmiştir. ${ }^{30}$

Sodyum florür $(\mathrm{NaF})$ içeren kavite vernikleri ve stannöz florür içeren jeller ve iyontoforez ile sodyum florür uygulanması dentin hassasiyetinin tedavisinde kullanılmaktadırlar. ${ }^{3,31-33} \quad$ Florürlü verniklerin ve iyontoforezin etkileri, $\mathrm{NaF}$ ile dentin sivisinın kalsiyum iyonları arasında meydana gelen reaksiyon ile dentin tübüllerinin ağızlarında biriken kalsiyum florür kristallerini oluşturarak tübülün tıkanmasına bağlıdır. Ayrıca bu kalsiyum florür tabakası asit atağına karşı diş yüzeyinde demineralizasyonun azaltılmasinda katk1 sağlayabilmektedir. ${ }^{3,8,31-33} \quad \% 5$ sodyum florür içerikli verniklerin etkinliklerini karşılaştırıldığ klinik çalışmalarda tedavi sonrasi 8-24 hafta arasinda hassasiyet şikâyetinin kontrol altına alınabildiğini bildirmişlerdir. ${ }^{31,32}$ Singal ve ark. 50 hastada yaptıkları klinik çalışmalarında hassasiyet tedavisinde iyontoforez ile \%2'lik sodyum florür solusyonu ile hidroxi-etil-metakrilat ve guluteraldehit (HEMA-G) içeren solusyon uygulamasının tedaviden hemen sonra, 2 hafta, 1 ve 3 ay sonra kontrollerinde her iki yöntemi de başarılı olarak saptamışlar ancak iyontoforez grubunu daha başarılı bulmuşlardır. ${ }^{33} \mathrm{DH}$ tedavisinde kullanılan bir diğer ajan ise oksalat bileşikleridir. Dentin yüzeyine uygulandıklarında dentindeki kalsiyum iyonlarıyla reaksiyona girerek dentin tübüllerini tıkayan çözünmeyen kristaller oluşturarak ve potasyum iyon salınımıyla sinir hücreleri üzerine inhibitör etkileri olduğu bildirilmiştir., ${ }^{2,34}$ Ferrik oksalat, potasyum oksalat ve fotokompleks içeren oksalatların kullanıldığı çalışmalarda dentin hassasiyetinin kontrolünde etkili oldukları bildirilmiştir. $^{35-37}$ Ancak generalize DH tedavisinde gastrik irritasyondan dolay1 dikkatli kullanılmalıdır. $^{3}$

Birçok topikal desensitivite edici ajanın dentin yüzeyine tutulumunun yetersiz olmasından dolayı etkileri kisa sürmektedir. Cam iyonomer, rezin modifiye cam iyonomerler/kompomerler, adeziv rezin primer ve adeziv rezin bonding sistemleri uygulandiktan sonra yapılarında kırık görülmediği sürece kabul edilebilir dayanıklılıkta dentin tübül tıkayıcıları olarak düşünülmektedir., 38 Dental yapıda bir kayıp olmadığında bonding ajanları endike olabilir. Anlık olarak etkindirler ve kolaylıkla ortadan kalkarlar. ${ }^{39}$ Rezin içerikli hidroksimetil metakrilat (HEMA), benzalkonyum klorit, gluteraldeit ve florit içeren dentin desensitivite ediciler immediate ve uzun dönem etkinlik göstermeleri ve dentin tübüllerini kapatmak için üretilmişlerdir. HEMA fiziksel olarak dentin tübülerini t1karken gluteraldehitte dentin tübül plasma proteinlerinin koagülasyonuna sebep olmaktadır. ${ }^{3,40}$ Rezin kompozitler, cam iyonomer ve rezin modifiye cam iyonomer simanlar örtü tabakası oluşturarak açık dentin tübül açıklılarını kapatırlar ancak restoratif materal kulanımı dental yapıda bir kayıp olduğunda ve lokalize vakalarında düşünülmelidir., ${ }^{2,8}$ Duran ve Şengün 52 hasta üzerinde yaptıkları çalışmada adeziv rezin bonding ve primer, HEMA, benzalkonyum klorit, gluteraldeit, florit içeren rezinler ve sadece sodyum-kalsiyum florit içerikli vernik gibi beş farklı desensitivite edici ajanın tedavi sonras1, 10. gün ve üç aylık kontrollerde değerlendirmişlerdir. Tüm grupların başlangıca göre hassasiyette belirgin azalma gösterdiği gruplar aras1 değerlendirmede ise adeziv rezin bond ve primer ajanın belirgin farkı rapor edilmiştir. $^{40}$

DH tedavisinde desensitivite edici ajanların yanı sıra günümüzde lazerler de kullanılmaktadırlar. Günümüzde diş hekimliğinde kullanılan lazerler iki ana grup: 1.Düşük güçteki helyum-neon (He- 
$\mathrm{Ne}$ ) ve gallium-aluminium-arsenide (GaAlAs) (Diyot) lazerler; 2.Orta güçteki neodmium-doped:yttrium- aluminiumgarnet (Nd:YAG), karbon dioksit $\left(\mathrm{CO}_{2}\right)$, erbium-doped:yttrium-aluminium-garnet (Er:YAG), erbium, chromiumdoped:yttrium-scandium-gallium-garnet (Er,Cr:YSGG) lazerler olarak sayılabilir. ${ }^{41-}$ ${ }^{43}$ Dentin üzerinde lazer irradyasyonunun etkisini açıklamak için; dentinin erime ve yeniden kristalizasyonuyla dentin tbüllerinin kapatılması, dentin lenfinin buharlatırılması, deprese sinir taşınımına bağlı analjezik etki ve dentin tübüllerinin tersiyer dentin ürünleriyle tıkanması gibi birçok faklı teori önerilmiştir. ${ }^{44-47}$

DH'nin tedavisinde $\mathrm{He}-\mathrm{Ne}$ lazer 1şınlarından faydanılan çalışmalarda etkinliğin $\% 5$ ile $\% 100$ arasında oldu bildirilmiştir. $\mathrm{He}-\mathrm{Ne}$ lazerin etki mekanizması için $\mathrm{A}$ ve $\mathrm{C}$ sinir lifleri reseptörleri üzerine etki etmediği, fakat aksiyon potansiyelini değiştirdiğini ve bu etkinin uzun sürdüğü bildirilmiştir. ${ }^{41,48}$

$\mathrm{DH}$ 'nin tedavisinde kullanılan diğer bir lazer de GaAlAs(diyot) lazer $660 \mathrm{~nm}$ den $904 \mathrm{~nm}$ ye kadar dalga boylarını üretebilmektedir. Düşük doz lazer tedavisinin hassasiyet üzerine etkinliği inceleyen birçok araştırmacı çeşitli dalga boylarında $20 \mathrm{~mW}$ ile $60 \mathrm{~mW}$ güç aralığında diyot lazerleri kullanılmıştır ve tedavi etkinliği \%30 ile \%100 oranlarında olduğu bildirilmiştir. ${ }^{41,44,49-51}$ Diyot lazerin maksimum gücü olan $60 \mathrm{~mW}$ mine veya dentin yüzeyine morolojik olarak etki etmez. Ancak $830 \mathrm{~nm}$ dalga boyundaki lazer enerjisinin küçük bir bölümü dental sert dokulardan pulpaya ulaşabilir. GaAlAs lazerin analjezik etkisi $\mathrm{C}$ sinir fibril sonlanmalarının depolarizasyonunu bloke etmesine bağlanmıştır. ${ }^{41,48}$ Analjezik etkisinin yanı sıra uzun zaman aralığında provake olmuş odontoblast stimulasyonu, irregüler tamir dentini üretimi ve dentin tübüllerinin tıkanması $\mathrm{DH}$ de ağrı baskilanmasının sebepleri olarak sayılabilir. ${ }^{50-53}$

$\mathrm{DH}$ 'nin tedavisinde orta güçteki lazerlerden $1064 \mathrm{~nm}$ dalga boyuna sahip
Nd:YAG lazerin genel olarak $1 \mathrm{~W}-2 \mathrm{~W}$ güç aralığında kullanıldığı çalışmalarda tedavi etkinliği \%5.2 ile \%100 arasında değiştiği belirtilmiştir. ${ }^{52,54-58} \mathrm{Nd}: Y A G$ lazer ışınlarının emilimini arttıran ve 1şınların daha iç bölgelere penetrasyonunu önleyerek pulpanın korunmasını sağlayan siyah mürekkep kullanılmasını öneren ve etkinliğin arttığını bildiren çalışmalar vardır. $^{41,55} \mathrm{Nd}: Y A G$ lazerin direkt sinir analjezisi ve dentin tübüllerinin ağzının daraltılması ve tıkanmasina sebep olarak hassasiyetin giderilmesinde etkili olduğu düşünülmektedir. Analjezik etkiyi hücre membranı permeabilitesinin değişimiyle oluştuğu ileri sürülmüştür. ${ }^{41,52,54-58}$ Ayrıca çalışmalarda $1.5 \mathrm{~W}$ altı güç parametrelerinde dentinde erime ve açık dentin kanallarının kapandığgi 1,5 W üzeri parametrelerde ise kök üzerinde çatlak ve fissürlerin görüldügü ve pulpa yaralanmas1 görülebileceği bildirilmiştir. ${ }^{54,59} \mathrm{CO}_{2}$ lazer de $\mathrm{DH}$ tedavisinde kullanılmaktadır. $\mathrm{CO}_{2}$ lazerin $\mathrm{DH}$ tedavisindeki etkinliği \%59 ile $\% 100$ arasında olduğu rapor edilmiştir. ${ }^{41,60}$ $\mathrm{CO}_{2}$ lazerin etki mekanizması, dentinin erimesi ile dentin kanallarının tıkanması ve daralması şeklinde açıklanmıştır. $\mathrm{CO}_{2}$ lazer ayrica dentin permeabilitesini azaltması yanında dentinde kurumaya da neden olduğu ve hassasiyette geçici rahatlamaya sebep olduğu bildirilmiştir. ${ }^{41,60}$

Termal yan etkileri sebebiyle Nd:YAG ve $\mathrm{CO}_{2}$ lazerlerden farklı lazer tiplerinin kullanılması

yönlendirmiştir. $^{60,61} \mathrm{Bu}$ amaçla Er:YAG ve Er,Cr:YSGG lazerler DH tedavisinde kullanılmıştır. Bu lazerlerin, termomekanik ablasyon mekanizmasi, bu dalga boylarındaki lazer enerjisinin de su molekülleri tarafindan maksimum derecede emilmesi ve dentindeki hidroksil gruplarını da hedef alması sebebiyle dental uygulamalarda termal olarak güvenli ve etkindirler. ${ }^{42,62} \quad$ Er:YAG lazer irradyasyonun $\mathrm{DH}$ nin tedavisinde klinik başarısı çalışmalarda gösterilmiştir. ${ }^{46,54,61,63}$ DH tedavisinde Er;Cr:YSGG lazeri ilk defa Yılmaz ve ark. kullanmışlardır. Tedavide etkinliğinin plaseboya göre 
üçüncü ayda da korunduğu bildirilmiștir. ${ }^{51}$ Er:YAG lazerin dalga boyunun $(2940 \mathrm{~nm})$ Er:Cr:YSGG lazerin dalga boyuna (2780 nm) yakın olması sebebiyle benzer özelliklere sahiptir. Erbiyum lazerin suda yoğun absorbsiyonu sonucu lazer irradyasyonu sonucu dentin lenfinin buharlaşmasıyla ekspoze dentin kanallarının içerisinde çözünmez tuzların depozisyonuyla dentin kanallarını tıkadığ ve ayrıca yüksek bakterisidal potansiyel ile ağr1 eşiğini düşüren enflamatuar medyatörelerin salınımı azaltarak dentin hassasiyetini azalttığı düşünülebilir. ${ }^{46,62,64}$ Lazer enerjisinin $\mathrm{OH}$ iyonları tarafindan daha fazla abzorbe edildiğinden yüzey sıcaklığının lokalize olarak artarak mine ve dentinin mineral yapisindaki kalsiyum/fosfat oranının belirgin bir biçimde artmasıyla çözünürlülüğün azalıp çürüklere karşı dirençli bir yüzey elde edilebildiğini bildirilmiştir. ${ }^{51,65}$

Farklı lazer tiplerinin karşılaştırılıp DH tedavisinde etkinliğini inceleyen araştırmalara bakılacak olursa; DH tedavisinde Nd: YAG ve Diyot etkinliğini değerlendirilen çalışma da, her iki lazer tipinin DH tedavisinde kullanılabileceği, Nd: YAG lazerin daha etkin olduğunu bildirilmiştir. ${ }^{52}$ Dişeti çekilmesi sebebiyle hassasiyet şikayeti olan 24 hastada Er: YAG, Nd:YAG ve Diyot lazerin etkinliklerini değerlendiren başka bir çalışmada Nd:YAG lazerin diğer lazer gruplarına göre 3 aylık kontrollerde daha başarılı olduğunu bildirmiştir. ${ }^{54} \mathrm{Nd}$ :YAG ve Er:YAG lazerin DH tedavisindeki etkinliğini değerlendirilen başka bir çalışmada, Nd:YAG lazerin daha etkili olduğunu rapor edilmiştir. ${ }^{61}$ Son olarak DH tedavisinde Er;Cr:YSGG ve Diyot lazerlerin kontrol grubu ile karşılaştırıldığı çalışmada her iki lazerinde 3.ay kontrollerinde DH kontrolünde etkin oldukları ve lazer tedavisi uygulanan gruplar arasında ise istatistiksel olarak anlamlı fark olmadığ 1 rapor edilmiştir. ${ }^{51}$ Lazerler ile çeşitli hassasiyet giderici materyallerin etkinliğinin karşılaştırıldığ 1 çalışmalar da vardır; lazerlerin daha başarılı ve etkili olduğunu ve bu etkilerinin uzun süreli olduğu rapor edilmiştir. ${ }^{44,66,67}$ GaAlAs, Nd:YAG, $\mathrm{CO}_{2}$ ve Er:YAG lazerlerin, sodyum florür jel ile birlikte kullanımları ve tek başlarına kullanımlarının tedavideki etkinliklerinin incelendiği araştırmalarda ise, desensitivite edici ajanla lazerin kombine kullanımlarının hassasiyet tedavisinde daha etkili oldukları bildirilmiştir. ${ }^{18,68,69}$

Son olarak DH nin konvansiyonel tedavisinde açığa çıkmış kök yüzeylerinin kapatılmasında periodontal plastik cerrahiden bahsedilebilir. Serbest dişeti grefti, laterale ya da koronale pozisyone flep, semilunar flep, subepitelyal bağ dokusu grefti ve yönlendirilmiş doku rejenerasyonu seçenekleri periodontal plastik cerrahide rutin olarak kullanılmaktadır. ${ }^{70-72}$ Ancak periodontal plastik cerrahinin sonuçları her zaman öngörülebilir değildir. Etkinlikleri sınırlı olabileceğinden dikkatli bir planlama gerekir. $^{70-73}$ Genel olarak periodontal plastik cerrahi, hassasiyet tedavisinde ilk olarak tercih edilen bir yöntem değildir.

\section{SONUC}

Dentin hipersensitivitesi, gerek etiyolojik, gerekse teşhis ve tedavi yönünden karmaşık ve bir semptomlar dizisidir. Teşhisinde, ekpoze dentinin genişliğinin ve etkenlerin saptanması ve elimine edilmesi gerekmektedir. Duyarlılığın önlenmesi için hekimin önerileri ve hasta bilgilendirmesi, etiyolojik faktörlerin eliminasyonunda çok önemlidir. $\mathrm{Bu}$ amaçla, travmatik olmayan diş firçalama teknikleriyle ilgili öneriler verilmeli; asidik diyet alınımı kontrol altına alınmalı ve dentinin ekspoze olmasına neden olabilecek alışkanlık, iatrojenik ve sistemik faktörler elimine edilerek doğal remineralizasyon yoluyla tübüllerin kapanmasına firsat tanınmalıdır. Başarı elde edilemediğinde tedavi, ağrının süresi ve şiddeti esas alınarak yapılmalı, tercih edilecek ajan uzun süreli tübül tıkayıcı etkiye sahip olmalıdır. 


\section{KAYNAKLAR}

1. Canadian Advisory Board on Dentin Hypersensitivity. Consensus-based recommendations for the diagnosis and management of dentin hypersensitivity. J Can Dent Assoc 2003;69:221-226.

2. Al-Sabbagh M, Brown A, Thomas MV. In-office treatment of dentinal hypersensitivity. Dent Clin North Am 2009;53:47-60. [CrossRef]

3. Porto IC, Andrade AK, Montes MA. Diagnosis and treatment of dentinal hypersensitivity. J Oral Sci 2009;51:323-332. [CrossRef]

4. Gilliam DG, Orchardson R. Advances in the treatment of root dentine sensitivity: mechanisms and treatmetn principles. Endod Top 2006;13:13-33.

5. Clayton DR, McCarthy D, Gillam DG. A study of the prevalence and distribution of dentine sensitivity in a population of 17-58-year-old serving personnel on an RAF base in the Midlands. J Oral Rehabil. 2002;29:1423. [CrossRef]

6. Dababneh RH, Khouri AT, Addy M. Dentine hypersensitivity - an enigma? A review of terminology, mechanisms, aetiology and management. Br Dent $\mathbf{J}$ 1999;11:606-611. [CrossRef]

7. Orchardson R, Gillam DG. Managing dentin hypersensitivity. J Am Dent Assoc 2006;137:990-998

8. Bartold PM. Dentinal hypersensitivity: a review. Aust Dent J 2006;51:212218. [CrossRef]

9. Rees JS, Addy M. A cross-sectional study of dentine hypersensitivity. J Clin Periodontol 2002;29:997-1003. [CrossRef]

10. West NX. Dentine hypersensitivity: preventive and therapeutic approaches to treatment. Periodontol 2000 2008;48:31-41. [CrossRef]

11. Orchardson R, Gangarosa LP Sr, Holland GR, Pashley DH, Trowbridge HO, Ashley FP, Kleinberg I, Zappa U. Dentine hypersensitivity-into the $21 \mathrm{st}$ century. Arch Oral Biol 1994;39:113119. [CrossRef]

12. Kielbassa AM. Dentine hypersensitivity: Simple steps for everyday diagnosis and management. Int Dent J 2002;52:394-396

13. Litonjua LA, Andreana S, Bush PJ, Cohen RE. Tooth wear: attrition, erosion, and abrasion. Quintessence Int 2003;34:435-446.

14. Wolff MS. Dentin hypersensitivity, the biofilm and remineralization: what is the connection? Adv Dent Res 2009;21:21-24.

15. Addy M. Dentine hypersensitivity: new perspectives on an old problem. Int Dent J 2002;52:387-375.

16. Drisko $\mathrm{CH}$. Dentine hypersensitivity dental hygiene and periodontal considerations. Int Dent J 2002;52,385-393.

17. Kleinberg I, Kaufman HW, Wolff M. Measurement of tooth hypersensitivity and oral factors involved in its development. Arch Oral Biol 1994;39:63-71. [CrossRef]

18. Kumar NG, Mehta DS. Short-term assessment of the Nd:YAG laser with and without sodium fluoride varnish in the treatment of dentin hypersensitivity--a clinical and scanning electron microscopy study. J Periodontol 2005;76:1140-1147. [CrossRef]

19. Davies R, Scully C, Preston AJ. Dentifrices--an update. Med Oral Patol Oral Cir Bucal 2010;15:976-982. [CrossRef]

20. Chu $\mathrm{CH}$, Lo ECM. Dentin hypersensitivity: a review. Hong Kong Dent J 2010;7:15-22.

21. Ayad F, Ayad N, Delgado E, Zhang YP, DeVizio W, Cummins D, Mateo LR. Comparing the efcacy in providing instant relief of dentin hypersensitivity of a new toothpaste containing $8.0 \%$ arginine, calcium carbonate, and $1450 \mathrm{ppm}$ fuoride to a benchmark desensitizing toothpaste containing $2 \%$ potassium 
ion and $1450 \mathrm{ppm}$ fuoride, and to a control toothpaste with $1450 \mathrm{ppm}$ fuoride: a three-day clinical study in Mississauga, Canada. J Clin Dent 2009; 20: 115-122.

22. Pradeep AR, Sharma A. Comparison of clinical efficacy of a dentifrice containing calcium sodium phosphosilicate to a dentifrice containing potassium nitrate and to a placebo on dentinal hypersensitivity: a randomized clinical trial. J Periodontol 2010;81:1167-1173. [CrossRef]

23. Lee SY, Kwon HK, Kim BI. Effect of dentinal tubule occlusion by dentifrice containing nano-carbonate apatite. J Oral Rehabil 2008;35:847-853. [CrossRef]

24. Orsini G, Procaccini M, Manzoli L, Giuliodori F, Lorenzini A, Putignano A. A double-blind randomizedcontrolled trial comparing the desensitizing efficacy of a new dentifrice containing carbonate/hydroxyapatite nanocrystals and a sodium fluoride/potassium nitrate dentifrice. J Clin Periodontol 2010;37:510-517.

25. Pereira R, Chava VK. Efficacy of a $3 \%$ potassium nitrate desensitizing mouthwash in the treatment of dentinal hypersensitivity. J Periodontol 2001;72:1720-1725. [CrossRef]

26. Cuesta Frechoso $S$, Mene 'ndez $M$, Guisasola C, Arregui I, Tejerina JM, Sicilia A. Evaluation of the efficacy of two potassium nitrate bioadhesive gels $(5 \%$ and $10 \%)$ in the treatment of dentine hypersensitivity. A randomised clinical trial. $\mathrm{J}$ Clin Periodontol 2003;30:315-320.

27. Orchardson R, Gillam DG. The efficacy of potassium salts as agents for treating dentin hypersensitivity. $\mathbf{J}$ Orofac Pain 2000;14:9-19.

28. Suge $T$, Ishikawa $K$, Kawasaki A, Yoshiyama M, Asaoka K, Ebisu S. Effects of fluoride on the calcium phosphate precipitation method for dentinal tubule occlusion. J Dent Res 1995;74:1079-1085. [CrossRef]

29. Cherng AM, Chow LC, Takagi S. Reduction in dentin permeability using mildly supersaturated calcium phosphate solutions. Arch Oral Biol 2004;49:91-8. [CrossRef]

30. Yates R, Owens J, Jackson R, Newcotnbe RG, Addy M. A splitmouth placebo-controlled study to determine the effect of amorphous calcium phosphate in the treatment of dentine hypersensitivity. J Clin Periodontol 1998;25:687-692. [CrossRef]

31. Hoang-Dao BT, Hoang-Tu H, TranThi NN, Koubi G, Camps J, About I. Clinical efficiency of a natural resin fluoride varnish (Shellac F) in reducing dentin hypersensitivity. J Oral Rehabil 2009;36:124-131. [CrossRef]

32. Ritter $A V$, de $L$ Dias $W$, Miguez $P$, Caplan DJ, Swift EJ Jr. Treating cervical dentin hypersensitivity with fluoride varnish: a randomized clinical study. J Am Dent Assoc 2006; 137:1013-1020

33. Singal P, Gupta R, Pandit N. $2 \%$ sodium fluoride-iontophoresis compared to a commercially available desensitizing agent. J Periodontol 2005;76:351-357. [CrossRef]

34. Cunha-Cruz J, Stout JR, Heaton LJ, Wataha JC. Dentin Hypersensitivity and Oxalates: a Systematic Review. J Dent Res. 2010; doi:10.1177/0022034510389179.

[CrossRef]

35. Gillam DG, Newman HN, Davies EH, Bulman JS, Troullos ES, Curro FA. Clinical evaluation of ferric oxalate in relieving dentine hypersensitivity. J Oral Rehabil 2004;31:245-250. [CrossRef]

36. Pillon FL, Romani IG, Schmidt ER. Effect of a $3 \%$ potassium oxalate topical application on dentinal hypersensitivity after subgingival 
scaling and root planing. J Periodontol 2004;75:1461-1464. [CrossRef]

37. Pereira JC, Martinelli AC, Santiago S. Treating hypersensitive dentin with three different potassium oxalatebased gel formulations: a clinical study, Rev FOB 9 2001;123-130.

38. Tay FR, Gwinnett AJ, Pang KM, Wei SH. Structural evidence of a sealed tissue interface with a total-etch wetbonding technique in vivo. J Dent Res 1994;73:629-636.

39. $\mathrm{Hu} \mathrm{J}, \mathrm{Zhu} \mathrm{Q}$. Effect of immediate dentin sealing on preventive treatment for postcementation hypersensitivity. Int J Prosthodont 2010;23:49-52.

40. Duran I, Sengun A. The long-term effectiveness of five current desensitizing products on cervical dentine sensitivity. J Oral Rehabil 2004;31:351-356. [CrossRef]

41. Kimura $Y$, Wilder-Smith $P$, Yonaga $\mathrm{K}$, Matsumoto K. Treatment of dentine hypersensitivity by lasers: a review. J Clin Periodontol 2000;27:715-21. [CrossRef]

42. Dederich DN, Bushick RD. Lasers in dentistry: separating science from hype. J Am Dent Assoc 2004;135:20412.

43. Walsh LJ. The current status of laser applications in dentistry. Aust Dent J 2003;48:146-155. [CrossRef]

44. Corona SA, Nascimento TN, Catirse AB, Lizarelli RF, Dinelli W, PalmaDibb RG. Clinical evaluation of lowlevel laser therapy and fluoride varnish for treating cervical dentinal hypersensitivity. J Oral Rehabil 2003;30:1183-1189. [CrossRef]

45. Moritz A, Schoop U, Goharkhay K, Aoid M, Reichenbach P, Lothaller MA, Wernisch J, Sperr W. Long-term effects of $\mathrm{CO} 2$ laser irradiation on treatment of hypersensitive dental necks: results of an in Vivo study. J Clin Laser Med Surg 1998;16:211215.

46. Schwarz F, Arweiler N, Georg $T$, Reich E. Desensitizing effects of an
Er:YAG laser on hypersensitive dentine. J Clin Periodontol 2002;29:211-215. [CrossRef]

47. Yilmaz HG, Cengiz E, KurtulmusYilmaz S, Leblebicioglu B. Effectiveness of Er,Cr:YSGG laser on dentine hypersensitivity: a controlled clinical trial. J Clin Periodontol 2011; doi:10.1111/j.1600051X.2010.01694.x. [CrossRef]

48. Walsh LJ. The current status of low level laser therapy in dentistry. Part 2. Hard tissue applications. Aust Dent J 1997;42:302-306. [CrossRef]

49. Sicilia A, Cuesta-Frechoso $S$, Suárez A, Angulo J, Pordomingo A, De Juan P. Immediate efficacy of diode laser application in the treatment of dentine hypersensitivity in periodontal maintenance patients: a randomized clinical trial. J Clin Periodontol 2009;36:650-660. [CrossRef]

50. Pesevska S, Nakova $M$, Ivanovski $K$, Angelov N, Kesic L, Obradovic R, Mindova S, Nares S. Dentinal hypersensitivity following scaling and root planing: comparison of low-level laser and topical fluoride treatment. Lasers Med Sci 2010;25:647-650. [CrossRef]

51. Yilmaz HG, Kurtulmus-Yilmaz S, Cengiz E, Bayindir $\mathrm{H}$, Aykac $\mathrm{Y}$. Clinical evaluation of Er,Cr:YSGG and GaAlAs laser therapy for treating dentin hypersensitivity: A randomized clinical trial. J Dent 2011; doi:10.1016/j.jdent.2011.01.003. [CrossRef]

52. Dilsiz A, Canakci V, Ozdemir A, Kaya Y. Clinical evaluation of $\mathrm{Nd}$ :YAG and 685-nm diode laser therapy for desensitization of teeth with gingival recession. Photomed Laser Surg 2009;27:843-848. [CrossRef]

53. Ferreira AN, Silveira L, Genovese WJ, de Araújo VC, Frigo L, de Mesquita RA, Guedes E. Effect of GaAIAs laser on reactional dentinogenesis induction 
in human teeth. Photomed Laser Surg 2006;24:358-365. [CrossRef]

54. Dilsiz A, Aydin T, Canakci V, Gungormus M. Clinical evaluation of Er:YAG, Nd:YAG, and diode laser therapy for desensitization of teeth with gingival recession. Photomed Laser Surg 2010; 28 Suppl 2: S11-17. [CrossRef]

55. Yonaga K, Kimura Y, Matsumoto K. Treatment of cervical dentin hypersensitivity by various methods using pulsed Nd:YAG laser. J Clin Laser Med Surg 1999;17:205-210.

56. Gutknecht N, Moritz A, Dercks HW, Lampert F. Treatment of hypersensitive teeth using neodymium:yttrium-aluminum-garnet lasers: a comparison of the use of various settings in an in vivo study. $J$ Clin Laser Med Surg 1997;15:171174.

57. Lier BB, Rösing CK, Aass AM, Gjermo P. Treatment of dentin hypersensitivity by $\mathrm{Nd}$ :YAG laser. J Clin Periodontol 2002;29:501-506. [CrossRef]

58. Lan WH, Liu HC. Treatment of dentin hypersensitivity by $\mathrm{Nd}$ :YAG laser. J Clin Laser Med Surg 1996;14:89-92. [CrossRef]

59. Lan WH, Liu HC. Sealing of Human Dentinal Tubules by Nd:YAG Laser. J Clin Laser Med Surg 1996; 13: 32933.

60. Moritz A, Schoop U, Goharkhay K, Aoid M, Reichenbach P, Lothaller MA, Wernisch J, Sperr W. Long-term effects of $\mathrm{CO} 2$ laser irradiation on treatment of hypersensitive dental necks: results of an in Vivo study. J Clin Laser Med Surg 1998;16:211215.

61. Birang R, Poursamimi J, Gutknecht N, Lampert F, Mir M. Comparative evaluation of the effects of Nd:YAG and Er:YAG laser in dentin hypersensitivity treatment. Lasers Med Sci 2007;22:21-24. [CrossRef]
62. van As G. Erbium lasers in dentistry. Dent Clin North Am 2004;48:10171059.

63. Cakar G, Kuru B, Ipci SD, Aksoy ZM, Okar I, Yilmaz S. Effect of Er:YAG and $\mathrm{CO} 2$ lasers with and without sodium fluoride gel on dentinal tubules: a scanning electron microscope examination. Photomed Laser Surg 2008;26:565-571.

64. Hossain M, Nakamura Y, Yamada Y, Kimura Y, Matsumoto N, Matsumoto K. Effects of Er,Cr:YSGG laser irradiation in human enamel and dentin: ablation and morphological studies. J Clin Laser Med Surg 1999;17:155-159.

65. Secilmis A, Altintas S, Usumez A, Berk G. Evaluation of mineral content of dentin prepared by erbium, chromium:yttrium scandium gallium garnet laser. Lasers Med Sci 2008;23:421-425. [CrossRef]

66. Tengrungsun $T$, Sangkla W. Comparative study in desensitizing efficacy using the GaAlAs laser and dentin bonding agent. J Dent 2008;36:392-395. [CrossRef]

67. Moritz A, Gutknecht N, Schoop U, Goharkhay K, Ebrahim D, Wernisch J, Sperr W. The advantage of CO2treated dental necks, in comparison with a standard method: results of an in vivo study. The advantage of $\mathrm{CO} 2-$ treated dental necks, in comparison with a standard method: results of an in vivo study. J Clin Laser Med Surg 1996; 14:27-32.

68. Ipci SD, Cakar G, Kuru B, Yilmaz S. Clinical evaluation of lasers and sodium fluoride gel in the treatment of dentine hypersensitivity. Photomed Laser Surg 2009;27:85-91. [CrossRef]

69. Liu HC, Lan WH. The combined effectiveness of the semiconductor laser with duraphat in the treatment of dentin hypersensitivity. J Clin Laser Med Surg 1994;12:315-319.

70. Chambrone L, Chambrone D, Pustiglioni FE, Chambrone LA, Lima 
LA. Can subepithelial connective tissue grafts be considered the gold standard procedure in the treatment of Miller Class I and II recession-type defects? J Dent 2008;36:659-671. [CrossRef]

71. Chambrone L, Lima LA, Pustiglioni FE, Chambrone LA. Systematic review of periodontal plastic surgery in the treatment of multiple recessiontype defects. J Can Dent Assoc 2009;75:203a-203f.

72. Chambrone L, Sukekava F, Araújo MG, Pustiglioni FE, Chambrone LA,
Lima LA. Root-coverage procedures for the treatment of localized recession-type defects: a Cochrane systematic review. J Periodontol 2010;81:452-478. [CrossRef]

73. Al-Zahrani MS, Bissada NF. Predictability of connective tissue grafts for root coverage: clinical perspectives and a review of the literature. Quintessence Int 2005;36:609-616. 